\title{
Massive spontaneous retroperitoneal hemorrhage induced by enoxaparin and subsequent abdominal compartment syndrome requiring surgical decompression: A case report and literature review
}

\author{
Benjamin Quartey, Jeffrey Nelson
}

\begin{abstract}
Introduction: Spontaneous retroperitoneal hemorrhage from the use of enoxaparin is very rare but can be fatal. Although most cases are treated by conservative means, there may be a role for surgical intervention. Case report: We present the case of a 77-year-old man who developed a large retroperitoneal hemorrhage during treatment for pulmonary embolism and atrial flutter with enoxaparin in which supportive measures failed and necessitated surgical correction. Conclusion: This case adds to the growing number of cases of enoxaparin induced spontaneous retroperitoneal hemorrhage and the importance of surgical intervention when conservative management fails.
\end{abstract}

Keywords: Retroperitoneal hemorrhage, Enoxaparin treatment, Compartment syndrome, Surgical evacuation

Benjamin Quartey', Jeffrey Nelson²

Affiliations: ${ }^{1}$ General Surgery, Department of Surgery, National Capital Consortium, National Naval Medical Center, Bethesda, Maryland, USA; ${ }^{2}$ General/Colorectal Surgery, Department of Surgery/Colorectal Surgery, National Capital Consortium, Walter Reed Army Medical Center, Washington, DC, USA.

Corresponding Author: Benjamin Quartey, 8901

Wisconsin Ave, Bethesda, MD 20889; USA; Ph: 301295-4442; Fax: 301-295-0959 Email:

Benjamin.Quartey@med.navy.mil

Received: 05 May 2011

Accepted: 20 August 2011

Published: 01 October 2011
$* * * * * * * * *$

Quartey B, Nelson J. Massive spontaneous retroperitoneal hemorrhage induced by enoxaparin and subsequent abdominal compartment syndrome requiring surgical decompression: A case report and literature review. International Journal of Case Reports and Images 2011;2(10):14-18.

$$
* * * * * * * * *
$$

doi:10.5348/ijcri-2011-10-60-CR-4

\section{INTRODUCTION}

Retroperitoneal hemorrhage is one of the severe complications of enoxaparin, a low-molecular-weight heparin (LMWH) approved by the Unites States Food and Drug Administration (FDA) in 1993 for the treatment of deep venous thrombosis (DVT), and pulmonary embolism (PE). Since 1993, less than twenty cases of enoxaparin induced retroperitoneal hemorrhage have been reported in the English literature. The complication profile of enoxaparin comes from these few case reports. Therefore, we add to this limited database another case of enoxaparin induced retroperitoneal hemorrhage, which led to abdominal compartment syndrome with subsequent decompressive laparotomy and evacuation of the hematoma.

\section{CASE REPORT}

A 77-year-old white male with a past medical history significant for hypertension, coronary artery disease, and hyperlipidemia was transferred from an outside hospital to our Emergency Department due to recurrent atrial flutter. The patient presented to the 
outside facility complaining of cough, pleuritic chest pain and shortness of breath for three weeks. His vital signs were normal except for a heart rate of 150 beats per minute. Pertinent work up included an electrocardiogram which showed atrial flutter waves, normal cardiac enzymes, a chest X-ray which showed a retrocardiac opacity, a normal complete blood count, a fibrin D-Dimer of $1.25 \mathrm{mcg} / \mathrm{mL} \mathrm{FEU} \mathrm{(normal} 0.22-$ o.39), an intermediate probability ventilationperfusion lung scan, and a negative bilateral lower extremity duplex ultrasound for deep vein thrombosis (DVT).

On presentation to our facility, he had a heart rate of 130 beats $/ \mathrm{min}$, blood pressure of $130 / 70 \mathrm{mmHg}$ and an oxygen saturation of $99 \%$ on three liters of oxygen by nasal cannula. Focused physical examination revealed a well hydrated man, in no acute distress, with inspiratory wheezing and irregular heart rhythm. His white blood cell count was $10,000 / \mathrm{mm}^{3}$ (normal $3.6-10.6 / \mathrm{mm}^{3}$ ), blood urine nitrogen of $23 \mathrm{mg} / \mathrm{dL}$ (normal 9-20 mg/dL), creatinine $1.14 \mathrm{mg} / \mathrm{dL}$ (normal $0.7-1.2 \mathrm{mg} / \mathrm{dL}$ ), thyrotropin of $1.07 \mathrm{mcIU} / \mathrm{mL}$ (normal 0.34-4.82 $\mathrm{mcIU} / \mathrm{mL}$ ), international normalized value (INR) of 1.0 (range - 2.0-4.5) and fibrin D-Dimers of $1.25 \mathrm{mcg} / \mathrm{mL}$ FEU (normal 0.22-0.39).

The patient was admitted to the cardiac care unit (CCU) for hemodynamic monitoring and was placed on diltiazem drip at $10 \mathrm{mg} /$ hour. A computed tomography (CT) PE/DVT scan was obtained due to sudden increasing oxygen requirement, and low grade fever which showed sub-segmental pulmonary emboli. Enoxaparin (weight based) $80 \mathrm{mg}$, subcutaneous every 12-hours was initiated. Patient subsequently underwent uncomplicated direct current (DC) cardioversion with complete resolution of his atriatachyarrhythmia after failed therapy with several antiarrhythmia medications including metoprolol, digoxin and esmolol drip.

Ninety-six hours after the initial enoxaparin treatment, the patient became hypotensive with a blood pressure of $80 / 40 \mathrm{mmHg}$, a heart rate of 90 beats/min, a new severe left lower quadrant tenderness and significant ecchymosis at the enoxaparin injection site (left side of the abdomen). His hemoglobin $(\mathrm{Hg})$ dropped from 14 to $11.4 \mathrm{mg} / \mathrm{dL}$ (normal 12.8-17.7 mg/dL) within six hours. Enoxaparin was discontinued and he was transfused with six units of packed red blood cells (PRBC), two units of fresh frozen plasma (FFP), followed by 2.5 liters of crystalloid, one liter of colloid, and $10 \mathrm{mg}$ of vitamin K. An emergent contrast enhanced CT scan demonstrated a large left retroperitoneal hemorrhage $(13 \times 8 \mathrm{~cm})$ and bilateral intramuscular iliopsoashematoma (1.7 x 1.7 and $2.2 \times 2.2 \mathrm{~cm}$ ) (Figure 1). A decision was made to continue the supportive measures after the diagnosis of retroperitoneal hematoma was made. However, the patient oxygen requirement increased, urine output remained marginal, hemoglobin continued to drop $(9.3 \mathrm{mg} / \mathrm{dL})$, bladder pressure increased from 5 to $14 \mathrm{mmHg}$, and creatinine was $1.8 \mathrm{mg} / \mathrm{dL}$. A repeat non-contrast CT

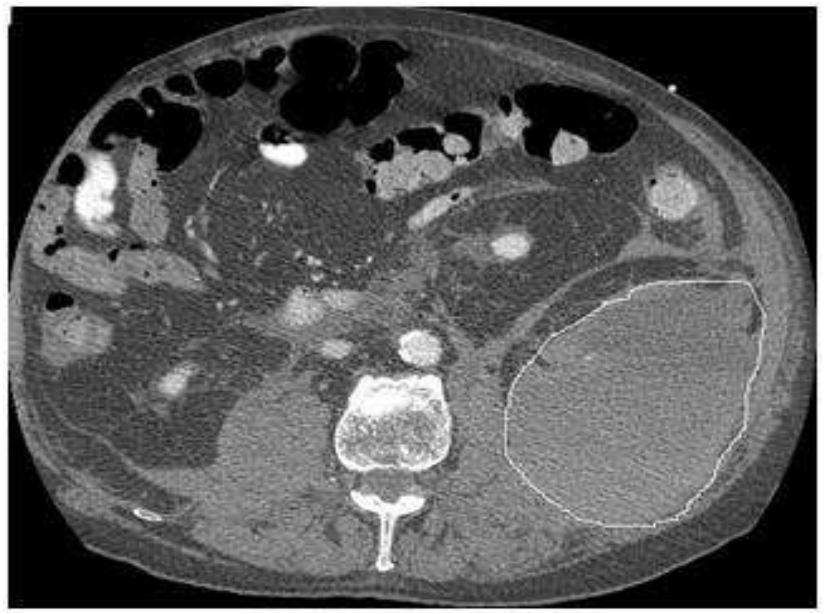

Figure 1: Initial contrast enhanced CT scan of the abdomen and pelvic showing large retroperitoneal hemorrhage.

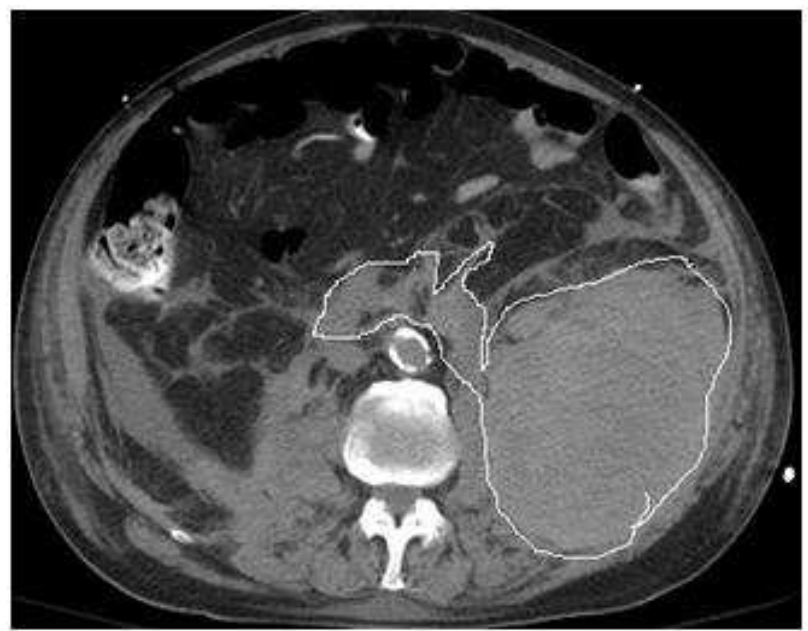

Figure 2: Repeat non-contrast CT scan of the abdomen and pelvic after 48 hours showed expansion of the retroperitoneal hematoma.

scan of the abdomen and pelvic showed expansion of the retroperitoneal hematoma (Figure 2). Patient became hemodynamically unstable and attempt were made to localize any bleeding vessels angiographically, but was unsuccessful (Figure $3 \mathrm{~A}, \mathrm{~B}$ ).

The patient was taken to the operation theater due to unstable hemodynamics, respiratory insufficiency, renal failure, suspected abdominal compartment syndrome and the possibility of ongoing bleeding. During exploration via a midline incision, a large retroperitoneal hematoma was found displacing the left colon medially. The left colon was mobilized in the usual fashion; the retroperitoneum was opened followed by packing with moist sponges, then gentle evacuation of the hematoma was done. No active bleeding was noted. The patient's pulmonary status, hemodynamic parameters and urine output improved 

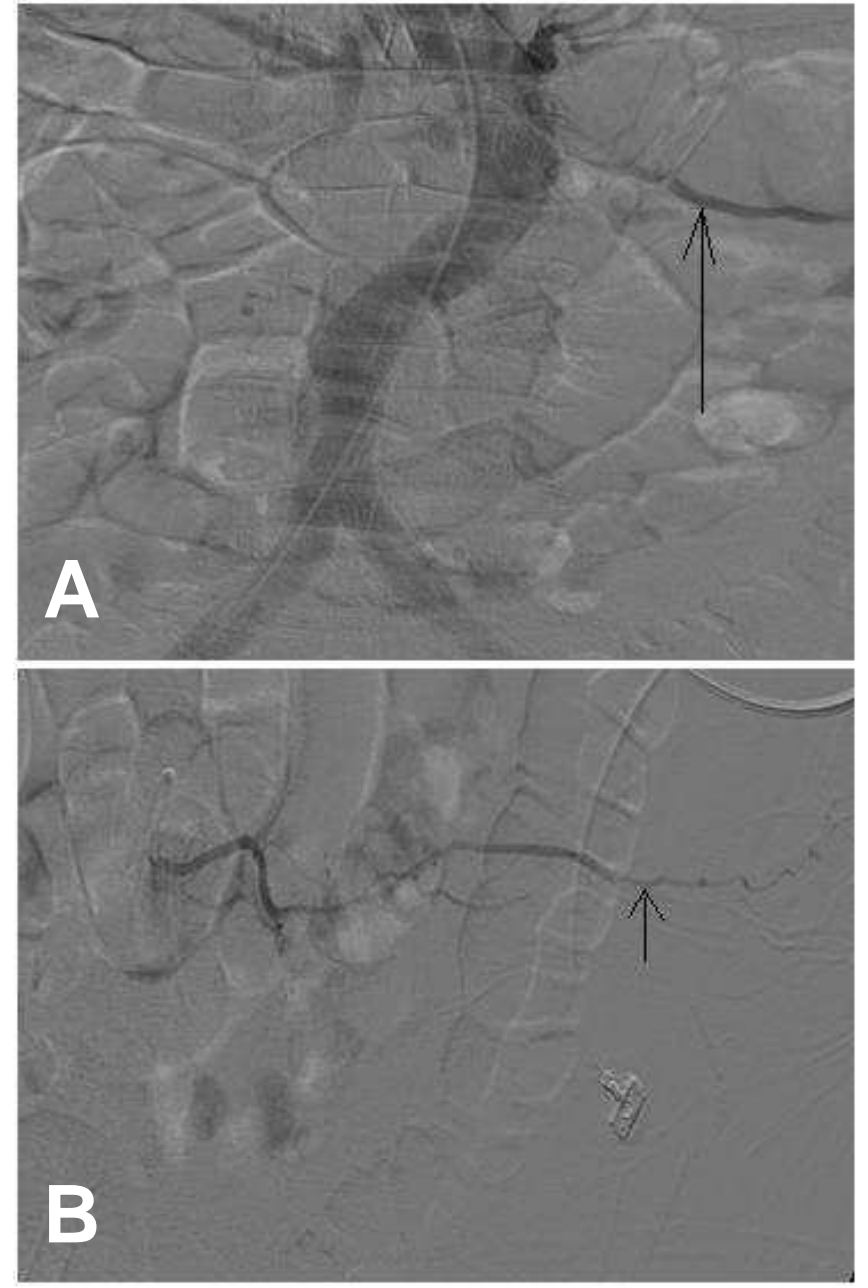

Figure 3: A) Normal Aortogram showing lumbar artery, B) Normal lumbar artery.

immediately. Due to the severe bowel edema from the resuscitation efforts, as well as the packing, abdomen was left open and closed over a negative pressure wound therapy. Intraoperatively the patient received six units of PRBC's, two units of FFP, one unit of cryoprecipitate, one unit of platelets and 4.5 liters of crystalloid. Patient required serial re-exploration, irrigation, and finally fascia closure 96-hours after the first exploration. Post-operative course was uncomplicated and patient was discharged home eighteen days after initial surgery.

\section{DISCUSSION}

Enoxaparin, a low-molecular-weight heparin (LMWH), is FDA approved for treatment of acute deep vein thrombosis (DVT) and pulmonary embolism (PE). It remains the most prescribed anticoagulant due to its safety, effectiveness, easy outpatient use and less hematologic monitoring $[1,2]$. Based on these unique profiles, The Seventh American College of Chest
Physician's Conference on Antithrombotic Therapy preferred LMWH's, such as enoxaparin, as compared with unfractionated heparin (UFH) for treatment and prophylaxis of thromboembolic disease [3]. Despite the above advantages over other anticoagulation agents, enoxaparin is not without complications. One of the most feared and serious of these is retroperitoneal hemorrhage which accounts for about $5 \%$ of enoxaparin induced complications [4]. Age over 65 years, renal insufficiency, and concomitant use of aspirin are some known risk factors for retroperitoneal hemorrhage with enoxaparin [5, 6]. With all of these risk factors, the common denominator is a decrease in renal clearance of enoxaparin. As shown in table 1, approximately $50 \%$ of patients had renal insufficiency as one of the risk factors, and our patient was no exception with a baseline creatinine of $1.14 \mathrm{mg} / \mathrm{dL}$.

Due to paucity of cases, there is no classic clinical presentation for enoxaparin induced retroperitoneal hematoma. The common presenting symptoms reported in literature are sudden onset of lower abdominal or flank pain, severe flank bruising, and shock [7]. Initial supportive care is the cornerstone of management and this includes crystalloid resuscitation, transfusion with packed red blood cells, correction of coagulopathy with fresh frozen plasma and cessation of all anticoagulation as well as monitoring in an intensive care unit setting [5]. If conservative management fails, open or percutaneous surgical evacuation is the next step. Only four open surgical evacuation cases has been reported in the literature and most of these cases involved hemodynamically unstable patients with suspected ongoing bleeding and impending compartment syndrome $[5,7,8]$. The major complication from retroperitoneal hematoma is further organ damage due to abdominal compartment syndrome caused by the expansion of the hematoma in the limited retroperitoneal space. This is the main indication for surgical evacuation and manifests as impaired cardiac output, respiratory insufficiency, obstructive nephropathy leading to oliguria, hypotension and intestinal ischemia [7].

Abdominal compartment syndrome (ACS) is defined as sustained intra-abdominal pressure (IAP) $>20 \mathrm{mmHg}$ associated with new organ dysfunction or failure [9]. If IAP $>12 \mathrm{~mm} \mathrm{Hg}$, this is refer to as intraabdominal hypertension (IAH). Normal IAP is 5-7 $\mathrm{mmHg}$ in critical ill patient [9]. IAH is graded as follows: grade I: IAP $12-15 \mathrm{mmHg}$, grade II: IAP $16-$ 20mmHg, grade III: IAP 21-25 mmHg, and grade IV: IAP $>25 \mathrm{mmHg}$. Our patient had grade $1 \mathrm{IAH}$ with more than two end organ dysfunction even though his IAP $<20 \mathrm{mmHg}$. Since ACS is a clinical diagnosis supported by objective values, surgical intervention in this patient was warranted. In fact, waiting to achieve IAP $>20 \mathrm{mmHg}$ in this particular patient would have been very detrimental considering the high morbidity and mortality associated with ACS.

Surgical decompression is $93 \%$ effective in reversing the organ dysfunction associated with 
Table 1: Enoxaparin induced retroperitoneal hematoma cases requiring decompression.

\begin{tabular}{lllllll}
\hline Author and year & Age(yr) & Indication & $\begin{array}{c}\text { Enoxaparin } \\
\text { twice a day }\end{array}$ & Risk factors & Therapy & Mortality \\
\hline Topgual, 2005 [5] & 70 & PE & N/A & W & Surgery & No \\
Ernists, 2005[7] & 71 & ACS & $1 \mathrm{mg} / \mathrm{kg}$ & ASA, P & Surgery & No \\
Dabney, 2001 [8] & 68 & DVT & $1 \mathrm{mg} / \mathrm{kg}$ & RF & Surgery & No \\
& 46 & DVT & $1 \mathrm{mg} / \mathrm{kg}$ & RF & Surgery & Surgery \\
Present case & 77 & PE, Atrial & $1 \mathrm{mg} / \mathrm{kg}$ & RF & No
\end{tabular}

Abbreviations: DVT ppx - Deep Vein thrombosis prophylaxis; ASA - Aspirin; RF - renal failure; W - warfarin; ACS - Acute Coronary syndrome; P - Plavix; PE - pulmonary embolism.

abdominal compartment syndrome and is associated with an overall survival of 59\% [10]. The four patients shown in table 1 survived this potentially fatal enoxaparin induced complication due to timely and appropriate surgical intervention after failed supportive measures. Surgical intervention should, therefore, not be delayed in unstable patients when conservative measures fail.

Moreover, from medication safety standpoint clinicians should exercise extreme caution when prescribing enoxaparin in patients with renal insufficiency and those over 6o years. More guidelines are needed since the current literature lack clear and specific information to identify which patient at risk for enoxaparin-induced hemorrhage.

\section{CONCLUSION}

Our patient was a 77-year-old man with difficult-tocontrol atrial flutter and pulmonary embolism who was treated with weight based enoxaparin and developed massive spontaneous retroperitoneal and bilateral intramuscular iliopsoas hematomas. Patient risk factors include age and mild renal insufficiency. The patient received massive resuscitation, but became hemodynamically unstable and finally developed abdominal compartment syndrome. Exploration showed evidence of early bowel ischemia. The acute clinical improvement after decompressive laparotomy and hematoma evacuation made surgery a life saving procedure in the management this patient. The fact that no patient who received surgery as part of their therapy for retroperitoneal hematoma died, as shown in table 1, raises questions about whether surgery should be used more often in these cases and what indications should be applied. More cases are needed to make this assessment, and this case adds to the series.

$* * * * * * * * *$

\section{Author Contributions}

Benjamin Quartey - Substantial contributions to conception and design, Acquisition of data, Analysis and interpretation of data, Drafting the article and revising it critically for important intellectual content, Final approval of the version to be published

Jeffrey Nelson - Substantial contributions to conception and design and analysis of data, Drafting the article and revising it critically for important intellectual content, Final approval of the version to be published

\section{Guarantor}

The corresponding author is the guarantor of submission.

\section{Conflict of Interest}

Authors declare no conflict of interest.

\section{Copyright}

(C) Benjamin Quartey et al. 2011; This article is distributed under the terms of Creative Commons attribution 3.0 License which permits unrestricted use, distribution and reproduction in any means provided the original authors and original publisher are properly credited. (Please see www.ijcasereportsandimages.com /copyright-policy.php for more information.) 


\section{REFERENCES}

1. Simmonneau G, Sors H, Charbonnier B, Page Y, Laaban JP, Azarian R, et al. A comparison of lowmolecular-weight heparin with unfractionated heparin for acute pulmonary embolism. N Engl J Med. 1997; 337(10):663-9.

2. Leizorovicz A, Simmonneau G, Decousus H, Boissel JP. Comparison of efficacy and safety of low molecular weight heparins and unfractionated heparin in initial treatment of deep venous thrombosis: a meta-analysis. BMJ. 1994;309(7):299304.

3. Geerts WH, Pineo GF, Heit JA, Berggvist D, Lassen MR, Colwell CW, et al. Prevention of venous thromboembolism: the Seventh ACCP Conference of Antithrombotic and Thrombolytic Therapy. Chest. 2004;126(3):338S-400S.

4. Buller HR, Agnelli G, Hull RD, Hyers TM, Prins MH, Raskob GE. Antithrombotic therapy for venous thromboembolic disease: the Seventh ACCP Conference on Antithrombotic and Thrombolytic Therapy. Chest 2004;126(3):401S-28S.

5. Topgul K, Uzun O, Anadol AZ, Gok A. Surgical management of enoxaparin-and /or warfarininduced massive retroperitoneal bleeding: report of a case and review of the literature. South Med J. 2005; 98(1):104-6.

6. Mrug M, Mishra PV, Lusane HC, Cunningham JM, Alpert MA. Hemothorax and retroperitoneal hematoma after anticoagulation with enoxaparin. South Med J. 2002;95(8):936-8.

7. Ernits M, Mohan PS, Fares LG 2nd, Hardy H 3rd. A retroperitoneal bleed induced by enoxaparin therapy. Am Surg. 2005;71(5):430-3.

8. Dabney A, Bastani B. Enoxaparin-associated severe retroperitoneal bleeding and abdominal compartment syndrome: a report of two cases. Intensive Care Med. 2001;27(12):1954-1957.

9. Cheatham ML, Malbrain ML, Kirkpatrick A, Sugrue M, Parr M, De Waele, et al. Results from the International Conference of Experts on Intraabdominal Hypertension and Abdominal Compartment Syndrome. II. Recommendation. Intensive Care Med. 2007;33(6):951-62.

10. Saggi BH, Sugerman HJ, Ivatury RR, Bloomfied GL. Abdominal Compartment Syndrome. J Trauma. 1998; 45:597-609. 